Juan Noemi C.

Profesor de Teología

Pontificia Universidad Católica de Chile

\title{
En la búsqueda de una teología de los "signos de los tiempos"
}

\section{PRÓLOGO}

En la introducción a mi tesis doctoral trataba de contextualizar su temática -Interpretación teológica del presente (1)- con la siguiente argumentación que me permito reproducir in extenso:

"Una de las aspiraciones básicas, por no decir la aspiración, del Concilio Vaticano II la constituyó el deseo de responder a las interrogantes que surgían de la situación del hombre contemporáneo. Este anhelo acabó por articularse, no sin dificultades (2), en un documento determinado, a saber, la Constitución Pastoral Gaudium et Spes. En este documento no solo se reconoce como un "oficio" que le incumbe a la Iglesia en razón de su misión testificadora de la verdad, salvífica y de servicio (3), el "escrutar" los signos de los tiempos e interpretarlos a la luz del evangelio" (4), sino que él mismo es un ensayo que pretende llevar a cabo dicha tarea interpretativa.

Como ha sido señalado más de una vez (5), lo significativo de Gaudium et Spes reside, más que en el aportar una respuesta, en el haber señalado la vigencia de una pregunta: el presente no puede ser considerado como mera situación a la cual se aplican las verdades evangélicas, sino que debe reconocérsele su carta de ciudadanía en el seno del círculo teológico (6); es

(1) Interpretación teológica del presente. Introducción al pensamiento de P. Tillich (Anales de la Facultad de Teología XXVI) Santiago de Chile 1976.

(2) Acerca de la génesis de Gaudium et Spes ver Ch. MOELLER, Die Geschichte der Pastoralkonstitution, en Lexikon für Theologie und Kirche: Das Zweite Vatikanische Konzil, Teil III, Freiburg 1968, p. 242-278.

(3) Conf. Gaudium et Spes 3, 2.

(4) Gaudium et Spes 4, 1.

(5) Conf. M. G. Mc. GRATH, Présentation de la Constitution L'Eglise dans le monde de ce temps, en L'Eglise dans le monde de ce temps, Tome II, Paris 1967, p. 17-30; Y. CONGAR, Eglise et monde dans la perspective de Vatican II, en L'Eglise dans le monde de ce temps, Tome III, Paris 1967, p. 15-41.

(6) Lo que en el vocabulario teológico tradicional equivale a reconocerle al presente el rango de "lugar teológico". Así por ejemplo Y. CONGAR, Eglise et monde dans la perspective de Vatican II, en L'Eglise dans le monde de ce temps, Tome III, Paris 1967, p. 29. Sobre la "función hermenéutica" 
preciso pues esforzarse en una interpretación teológica del mismo. Esta confesión del Magisterio, que para los oídos cristianos abiertos y expuestos desde decenios a la crítica ilustrada y al pensamiento histórico dista leguas de constituir una sorpresa, encontrará gran eco en el ambiente latinoamericano. Es así como el episcopado de ese continente, a pesar de haber sido señaladas las dificultades metodológicas de tal empresa interpretativa (7), en su deseo de traducir el Concilio Vaticano II a la realidad latinoamericana vuelve a utilizar el simple esquema de interpretación de Gaudium et Spes (8).

A diferencia de Europa donde la pregunta planteada por la Constitución Pastoral no es elaborada por parte de los teólogos en continuidad con el planteo que allí se ofrece (9), sino que sigue tratándose dentro del marco y con el instrumentario más refinado y complejo que ofrece la ya larga discusión en torno a una hermenéutica teológica que pueda validarse para el pensar histórico (10), el ensayo interpretativo de Medellín encuentra un desarrollo ulterior en la llamada Teología de la liberación, la cual se establece desde el punto de vista metodológico en continuidad con el llevado a cabo por los obispos (11). En verdad, es la misma duplicidad de momentos, uno -para usar la expresión no exenta de ambigüedad de un autorizado comentarista- "empírico" y el otro teológico, contenidos en el "método general" de Gaudium et Spes (12) y que

positiva que se le reconoce a una situación histórico-concreta en el Vaticano II insiste también W. KASPER, Die Methoden der Dogmatik. Einheit und Vielheit, München 1967, ver especialmente p. 43 donde se plantea la necesidad de una revisión de la doctrina tradicional de los loci theologici.

(7) Como bien lo delata la ponencia presentada por M. G. McGRATH, Los signos de los tiempos en América Latina hoy, en Segunda Conferencia General del Episcopado Latinoamericano, Medellín agosto, 26-septiembre 6 1968. La Iglesia en la actual transformación de América Latina a la luz del Concilio. I Ponencias, Bogotá 1969, p. 73-100.

(8) Conf. Segunda Conferencia General del Episcopado Latinoamericano, Medellín agosto 26-septiembre 6 1968. La Iglesia en la actual transformación de América Latina a la luz del Concilio II conclusiones. Bogotá 1969. Un buen comentario de la misma es el de J. COMBLIN, Réflexions sur la IIe. Conférence Générale de 1'Episcopat Latino-Américain à Medellin (24 Aout- 6 septembre 1968), en Cultures et Dévelopement 1 (1968) 678-684.

(9) El ensayo de M. D. CHENU, Les Signes des temps: réflexion théologique, en L'Eglise dans le monde de ce temps, Tome II, Paris 1967, p. 205-225, que trata de fundamentar como "categoría teológica" la expresión utilizada por Gaudium et Spes de "signa temporum”, constituye más bien una excepción.

(10) A este respecto resultan ilustrativos los aportes hechos ante el Coloquio promovido por el Centro Internacional de Estudios Humanísticos y por el Instituto Filosófico de Roma bajo la tutela de E. Castelli, del año 1971. Conf. La Théologie de l'Histoire. Herméneutitique et Eschatologie, Paris 1971; La Théologie de l'Histoire. Revélation et Histoire, Paris 1971. No deja de llamar la atención, por otra parte, la referencia que en algunas de las ponencias se hace al concepto de kairos. Igualmente podría mencionarse aquí la discusión europea en torno a la teología política. Conf. Diskussion zur "Politischen Theologie”, H. Peukert Ed., Mainz 1969 y más recientemente J.-P. THEVENAZ, Vérité d'espérance ou vérité de connaissance? Les enjeux de la théologie de Jürgen Moltmann, y M. XHAUFFLAIRE, La mémoire subversive du Christ: Introduction ä la pensée de Johann-Baptist Metz, ambos escritos en Etudes théologiques et religieuses 49 (1974) 225-248, 249-269 respectivamente.

(11) La misma definición de teología de G. Gutiérrez, "reflexión crítica de la praxis histórica a la luz de la fe", constituye una paráfrasis del propósito vaticano de "escrutar los signos de los tiempos e interpretarlos a la luz del evangelio". Conf. G. GUTIERREZ, Teología de la liberación. Perspectivas, Lima 1971, p. 31.

(12) Conf. M. G. McGRATH, Présentation de la Constitution L'Eglise dans le monde de ce temps, en L'Eglise dans le monde de ce temps, Tome II, Paris 1967, p. 27-28. 
reaparece en Medellín, la que se hace presente en la teología de la liberación. En lo único que se da una evolución es en el precisarse del análisis "empírico" que se hace preceder al teológico (13). Con ello se hace todavía más nítido el límite de un método que no logra mediar sino que solo yuxtapone al diagnóstico "empírico" sobre el presente uno teológico (14).

Esta insuficiencia metodológica, sin embargo, de ninguna manera invalida la legitimidad de la pregunta reconocida por Gaudium et Spes, acogida en Medellín y debatida en la Teología de la liberación, es decir, la legitimidad del problema de una interpretación teológica del presente. Dicha insuficiencia solo hace presente lo ineludible de la pregunta y la imposibilidad de proveer a la misma de una formulación más precisa.

El haber tratado de aclarar nuestra pregunta con referencia al proceso antes esbozado que va de Gaudium et Spes a la teología de la liberación, difícilmente podría llevar a la idea de que aquella tiene solo una vigencia parcial o regional (15). Solo hemos querido dar razón tanto de su actualidad así como de lo que condiciona su formulación genérica, a través de un ejemplo próximo".

A pesar de que la literatura sobre la temática suscitada por el planteo de Gaudium et Spes durante los últimos tres decenios es abundantísima (16), los avances en la superación de la "insuficiencia metodológica" detectada desde un comienzo son más bien escasos. La articulación de una teología de los "signos de los tiempos" sigue siendo todavía un programa que pareciera circunscribir una aporía metodológica insuperable. En todo caso, me atrevo a proponer algunas sugerencias suscitadas por dos publicaciones más recientes que me parecen abren pistas fructíferas de búsqueda.

(13) La constatación general de una situación de "mutación" y "desequilibrio" que se hace en Gaudium et Spes, conf. 5 y 8 , se precisa como diagnóstico de un proceso de liberación en marcha. Sobre el significado del procedimiento que posibilita tal precisión se puede ver F. CASTILLO y otros, Teoría y praxis en la Teología de la liberación, en Teología y Vida 15 (1974) 3-38.

(14) Esto no significa que la discusión se haya estancado en la constatación de un impasse, conf. antea nota 12; los esfuerzos se han concentrado en mostrar el papel mediador que a este respecto desempeñaría el concepto de praxis, conf. por ejemplo G. GIRARDI, Vérité et Libération: Les présupposés philosophiques d'une Théologie de la libération, en Etudes Théologiques 49 (1974) 271-297.

(15) Desde otros contextos se plantea la misma pregunta. Así por ejemplo K. RAHNER, en Handbuch der Pastoraltheologie, Bd. II/1, Freiburg 1966, p. 181-188. De un modo análogo C. Geffré ve que el desarrollo más reciente de la teología fundamental confronta con la misma pregunta, conf. C. GEFFRE, Historia reciente de la Teología Fundamental. Intento de interpretación, en Concilium 1969, No 46, 337-358, ver especialmente 357-358.

(16) Baste aquí remitir a la abundante bibliografía que aportan C. Casale, "Teología de los signos de los tiempos. Antecedentes y prospectivas del Concilio Vaticano II" en Teología y Vida 56 (2005) 527-569, Eduardo Silva, "Auscultar los signos de los tiempo presente y de la situación latinoamericana. Esbozo de algunos fenómenos a considerar para una interpretación teológica del presente" en Teología y Vida 56 (2005) 582-614, y Patricio Merino, "La categoría Signos de los Tiempos: sus significados e implicancias en el magisterio y en la teología católica”, en Anales de teología de la Universidad Católica de Concepción 8 (2006) 65-167. Me permito remitir también a una reciente publicación sobre el tema que trae una extensísima bibliografía: P. Hünermann Ed., Das zweite vatikanische Konzil und die Zeichen der Zeit heute Friburgo 2006, 610-656 y sobre cuyos aportes espero dar cuenta en el futuro. 


\section{LA “REVOLUCIÓN” DE GAUDIUM ET SPES}

Fue un breve escrito de Eric Borgman (17) el que me trajo a la memoria las líneas escritas hace más de treinta años que acaban de ser citadas en el prólogo. Borgman es tajante en su 'apreciación de Gaudium et Spes: "la revolución de la Gaudium et Spes sigue siendo la revolución que la Iglesia y la teología necesitan" (p. 500). ¿De qué revolución se trata? La de afirmar "que la Iglesia nace y se forma en medio del mundo. No se encuentra primero fuera del mundo... para luego unirse al mundo sino que se forma en medio del mundo" (p. 502). Este resituarse de la Iglesia "en medio del mundo" comporta algo "decisivo" "el mundo se convierte en el lugar teológico" (p. 503) y es así como el Vaticano II reconoce a la Iglesia "como un sacramento, o sea signo e instrumento de la unión íntima con Dios y de la unidad de todo el género humano-L.G. 1" (p. 503). De esta manera la polaridad iglesia-mundo queda referida a una instancia de unidad que la dinamiza y excluye una anquilosis o rigidización de dicha polaridad. En palabras del mismo Borgman, que se apoya en Gaudium et Spes 2: "Dios es ante todo el Creador y el Redentor del mundo que como tal se conoce especialmente dentro de la Iglesia donde está presente (LG 2-4). La Iglesia no existe para sí, sino que es signo e instrumento del envío de Dios, con lo que El adopta en su propia vida al mundo y a la humanidad. La Gaudium et Spes radicaliza esta concepción calificando al mundo con énfasis como teológico" (p. 503).

A mi parecer, Borgman hace presente y explicita de manera incisiva una cuestión que muchos comentaristas de Gaudium et Spes evaden y pone el dedo en la llaga cuando escribe: "La pregunta fundamental-teológica que implica la Gaudium et Spes, a menudo ni se ve siquiera, y aún menos se plantea de manera productiva: cómo abrir la investigación teológica a la situación actual. ¿Cómo puede la teología, cómo pueden los teólogos hablar responsablemente del mundo donde viven personas concretas como un lugar en el que son visibles los signos de Dios Creador, Redentor y Fin Ultimo, y cómo desde ahí se puede plantear a Dios y la historia de Dios con la humanidad?" (p. 505). No basta con postular genérica y abstractamente la unidad que valida la distinción entre iglesia-mundo como suele suceder cuando se hace referencia al "reino de Dios" como instancia escatológica (18).

(17) "Gaudium et Spes: el futuro olvidado de un documento revolucionario", en Concilium 2005, No 312, 499-508

(18) Como lo señalo en El mundo creación y promesa de Dios, Santiago 1996, 252-253: "Hablar del mundo como promesa de Dios no es un tema más para el Vaticano II, no se circunscribe a determinados textos, sino que estos últimos no son más que el precipitado de un horizonte y una inquietud que colora todo. Se trata de un enfoque o talante dialógico entre el mundo moderno y la Iglesia. El 'reino de Dios' es el eje que centra esta visión. Tanto la realidad de la Iglesia, el mundo, como la del hombre se definen en relación al reino de Dios como el designio evangélico definitivo y definitorio. Esta relatividad al reino de Dios no solo se enuncia puntualmente, sino que se articula linealmente. El reino de Dios es el sentido y el fin del hombre como designio sobre la historia de la humanidad y de cada hombre. En la vocación universal de la humanidad al reino, en el designio escatológico de Dios sobre todo lo existente, Iglesia y mundo se conjugan como realidades dinámicas, interdependientes entre sí y dependientes y relativas al reinado de Dios. Es decir, hombre, mundo e Iglesia no se conciben estáticamente y en dependencia de un parámetro abstracto de trascendencia, sino que el reino de Dios es la intencionalidad trascendental que permite configurar una historia de la humanidad, en la cual mundo e Iglesia se especifican como realidades dinámicas de un único designio salvífico de Dios" 
Se trataría de operativizar epistemológicamente un desafío que la Iglesia ha reconocido como verificación de su propia proexistencia para con el mundo (19). A ello apuntaba cuando, en referencia puntual a las "condiciones de posibilidad que tiene la iglesia para escrutar la democracia como signo de los tiempos" (20), anotaba: "El Concilio Vaticano II representa un reconocimiento solemne de la modernidad en sus aspectos positivos. Si se lee atentamente el capítulo dedicado a "La vida en la comunidad política" de G.S. (73-76) puede percibirse una clara ratificación del ideario democrático como un fenómeno histórico positivo, sin por ello canonizarse un modelo concreto de democracia. No es pues la ingenuidad lo que prolonga la suspicacia que anteriormente había prevalecido para juzgar la democracia, sino un reconocimiento que diferencia pero no contrapone la iglesia al mundo" (21); "el servicio al mundo no solo implica hacerse cargo del mundo como un referente externo a la iglesia, sino que requiere que esta se haga cargo ad intra de su propia mundanidad o laicidad" (22).

\section{EL REPLANTEO DE H.J. SANDER}

Una pista en la articulación del desafío epistemológico que nos plantea G.S. es la que nos propone H. J. Sander en un reciente escrito titulado "El singular actuar histórico de Dios, una pregunta de la topología plural de los signos del tiempo" (23). El punto de partida de su reflexión es que "la fe cristiana se contrapone a una relativización de la historia humana" y que consecuentemente "la teología lleva a cabo una no relativización de la historia"en la medida que "la historia de la salvación comporta una pretensión topológica"(p. 135). Así lo proclama G.S.10, 2: "Ella (la Iglesia) cree que la clave, el centro y el fin de toda la historia humana se encuentra en su Señor y Maestro. Afirma además la Iglesia que, en todos los cambios, subsisten muchas cosas que no cambian y que tienen su fundamento último en Cristo, que es El mismo ayer, hoy y por los siglos". De esta manera se opera una "desrelativización de las provisoriedades históricas" postulándose "una relatividad originaria entre dogma e historia" (24). Sander concluye: "Este camino de una relatividad entre cambio y permanencia se hace presente de manera más clara en la

(19) Conf. F. Parra, "Desafíos a la credibilidad de la Iglesia en América Latina", en Teología y Vida 45 (2004) 273-317, ver especialmente, 283-292.

(20) “Sobre la Democracia", en J. Noemi, La fe en busca de inteligencia, Santiago 1993, 188-189.

(21) o.a.c. 190

(22) o.a.c. 191 .

(23) "Das singuläre Geschichtshandeln Gottes - eine Frage der pluralen Topologie der Zeichen der Zeit", en Herders Theologischer Kommentar zum zweiten Vatikanischen Konzil 5 Theologische Zusammenschau und Perspektiven, Friburgo 2006, 134-147.

(24) o.a.c.136. A continuación Sander señala que la relatividad entre dogma e historia requiere necesariamente "encontrar un nuevo lenguaje que disuelva la contraposición entre verdades permanentes de los dogmas y cambiantes situaciones históricas del tiempo". Me permito al respecto recordar lo que apunto en referencia al "carácter histórico-escatológico del dogma cristiano": "Podría decirse que el dogma cristiano tiene una dimensión histórica en cuanto verdad dada (datum), heredada (traditum) y que interpela en el presente concreto (quaesitum)". J. Noemi, "Sobre la credibilidad del dogma cristiano", en Teología y Vida 45 (2004) 263. 
Constitución Pastoral del Vaticano II. Es el camino de la Pastoral, y este camino considera la relatividad de la historia por primera vez directa e inmediatamente como el lugar en la historia en el cual se habla de Dios. La relatividad no es soslayada, sino establecida en cuanto historia precisamente como principio de lugar teológico. Estos son los signos de los tiempos. En ellos aspiran los hombres al reconocimiento social de su dignidad; es precisamente una esperanza de la fe que esta aspiración tenga éxito y así que esos signos tengan un carácter relativo y limitado porque transitorio. Con ello acontece algo en referencia a la historia que Dios ha operado en Jesús con los hombres: Ella se hace accesible en lugares presentes y la teología de la historia se transforma en una forma de conocimiento topológico" (25).

A continuación Sander trata de aclarar como el Vaticano II operando un "rescate de la pretensión topológica" postula una "teología de la historia a partir de los signos del tiempo" (26). A su juicio, con la referencia que se hace en G.S.4 a "signos del tiempo" se establece una referencia a la historia bajo un respecto práctico: "El locus theologicus historia se concretiza con el término pastoral signos del tiempo". Del mismo modo la referencia implícita de G.S.11 a "signos del tiempo" también establece un nexo entre la realidad de Dios y la del tiempo, solo que la perspectiva es diversa. Mientras en G.S.4 es ascendente, es decir de los signos de los tiempos al evangelio, en G.S.11 la perspectiva es descendente, desde la fe (qua credit) a los "signos verdaderos de la presencia o designio de Dios". En ambos casos, sin embargo, se religa la realidad de Dios con la realidad de la historia humana. De esta manera queda excluido "un paralelismo (Parallelisierung) entre la realidad de Dios y la realidad del tiempo" y ambas realidades se postulan "unidas de alguna manera en el lugar de la historia". Esta relativización que se opera entre la realidad de Dios y la historia no se resuelve como "relativización de la presencia de Dios", sino que el Concilio le plantea a la teología la tarea de describir la "identificabilidad de Dios concretamente en el presente circunstancial de los hombres".

Dos son las indicaciones o advertencias que el texto conciliar le plantea al teólogo en esta tarea de mediar entre provisoriedad histórica y realidad divina. Se trata de detectar "signos" de una presencia o designio, es decir, los signos del tiempo tienen un carácter referencial que hace necesaria una criteriología de los mismos para discernir lo verdaderos de los falsos. La confección de tal criteriología es a juicio de Sander "el problema capital para una teología de la historia en base a los signos del tiempo".

La segunda indicación retoma un supuesto pneumatológico que expresa G.S.11: "El Pueblo de Dios, movido por la fe, por la cual cree que es guiado por el Espíritu Santo, que llena el orbe de la tierra, procura discernir en los acontecimientos, exigencias y deseos que comparte con sus contemporáneos, cuáles son los signos verdaderos de la presencia o del designio de Dios". La fe en la asistencia del Espíritu divino provee al pueblo de Dios de una seguridad pero no le confiere un conocimiento adicional cuantificable de antemano sobre los acontecimientos históricos. El supuesto de la asistencia del Espíritu promueve un dinamismo de búsqueda

(25) o.a.c. 136-137.

(26) o.a.c. $137-140$. 
del "Dios eterno" en los "fenómenos temporales de la historia". De esta manera la teología de la historia se ve urgida a integrar (sin abandonar) a la problemática genérica sobre el sentido de la historia una "gramática de carácter pastoral". Se introduce así "un factor de pluralización en la confrontación teológica con la historia": "El foco de la teología de la historia se desplaza desde un tema histórico central dominante a una diversidad de exigencias presentes".

De todo lo anterior decanta una "exigencia de pluralidad en el lugar de Dios en la historia" que conjugue "los muchos signos del tiempo y la una historia de la salvación” (27). La focalización unitaria sobre la historia que ha prevalecido en la teología de la historia se ve requerida a hacer también suya la diversidad de situaciones y así superar una mera "contraposición de pluralidad y singularidad" y mediar "al mismo tiempo entre una dimensión global y local". Así "la localidad (de los acontecimientos históricos) deviene un tema teológico", y "la base para expresar la singularidad reside en la pluralidad de los espacios históricos".

Sander concluye su propuesta con una acápite titulado: "El contenido revelatorio de los signos de los tiempos: distintos-lugares de la encarnación en la historia" (28). (Der offenbarende Gehalt der Zeichen der Zeit-Anders-Orte der Menschwerdung in der Geschichte). En él se sostiene que "el plural de los signos del tiempo en G.S.4 y 11 no obsta a la singularidad histórico-teológica de Cristo" (tal como esta se afirma en Lc.12, 56 s). Lo atestigua G.S.22 cuando dice que "solo en el misterio del Verbo encarnado se esclarece el misterio del hombre... Cristo manifiesta plenamente el hombre al mismo hombre y le descubre la grandeza de su vocación”. La pluralidad de los signos de los tiempos refuerza el singular del signo del tiempo y no relativiza a Jesucristo, en la medida que Este "hominem ipsi homini manifestat". "Los signos de los tiempos pertenecen a la revelación, en la medida que por una parte remiten a lo que se opone a la misma y por otra expresan en que precarios espacios presentes se hace visible tal revelación". Los signos de los tiempos no representan utopías de la fe ni tampoco fe en un irreversible y unívoco progresismo. "Más bien señalan distintos-lugares en la historia que hacen manifiesta la cuestionabilidad de sus expectativas de salvación y relativizan el progreso que no quiere reconocer a las víctimas de su desarrollo... muestran la alternativa de una esperanza de salvación que considera a las víctimas de la historia...".

\section{SUGERENCIAS}

A mi entender en el planteo de Borgman lo medular reside en un llamado a desabsolutizar la distinción entre Iglesia y mundo y atreverse a pensar -como a su juicio lo plantea el Vaticano II- a partir de la unidad que sustenta la real dimensión que comporta tal distinción y que establece a la Iglesia y el mundo como dimensiones de lo real que se requieren y compenetran. Así la Iglesia no es pensable como una exterioridad que simplemente se contrapone al mundo, ni este como realidad

(27) o.a.c. $140-142$.

(28) o.a.c. $142-144$. 
contradictoria de aquella. La Iglesia existe en el mundo y este no existe como mera realidad exterior a la Iglesia sino que también en ella. Tiene sentido hablar de Iglesia y mundo como una polaridad solo en la perspectiva con que Juan Pablo II lo hace con respecto a fe y razón: in altera enim altera invenitur et proprium habet spatium sui explicando (29). (una se encuentra en la otra y así tiene su propio espacio de realización). Solo superando el dualismo del recurso a la polaridad Iglesia-mundo como exterioridades contradictorias, como si fuesen dos mónadas irreconciliables, se recoge el horizonte teológico en el que el Concilio Vaticano II articula su discurso sobre los signos de los tiempos.

Debe recordarse además que, en la perspectiva del Vaticano II no solo se evita la contraposición entre Iglesia y mundo sino que se establece una positiva correlación recíproca entre ambos que excluye el considerar al mundo como mero polo negativo (30). El capítulo cuarto de la primera parte de Gaudium et Spes es meridiano al respecto cuando trata sobre "la relación mutua entre la Iglesia y el mundo" (G.S.40) y una vez que describe la "ayuda que la Iglesia procura prestar a cada hombre" (G.S.41-43) explicita la "ayuda que la Iglesia recibe del mundo actual" (G.S.44): "De la misma manera que interesa al mundo reconocer a la Iglesia como realidad social y fermento de la historia, también la propia Iglesia sabe cuánto ha recibido de la historia y evolución de la humanidad". Todavía más se reconoce que "para aumentar este intercambio (entre la Iglesia y las diferentes culturas de los pueblos), la Iglesia, sobre todo en nuestro tiempo, en que las cosas cambian con suma rapidez y los modos de pensar varían tanto, necesita, de modo peculiar, la ayuda de aquellos que, viviendo en el mundo, conocen a fondo las diferentes instituciones y disciplinas y comprenden la mentalidad, sea que se trate de creyentes o no creyentes".

Con respecto al proyecto de una "teología de la historia en base a los signos de los tiempos" que plantea Sander, me limito a plantear dos acotaciones elementales que me sugieren las dos "indicaciones" que él hace a partir del texto conciliar: "El pueblo de Dios, movido por la fe, por la cual cree que es guiado por el Espíritu del Señor, que llena el orbe de la tierra, procura discernir en los acontecimientos, exigencias y deseos que comparte con sus contemporáneos, cuáles son los signos verdaderos de la presencia o del designio de Dios" (G.S.11).

Con toda razón Sander señala la fe en la presencia y guía del Espíritu en la historia como supuesto fundamental de una teología de la historia que, sin embargo, apenas se ha articulado suficientemente al menos en el occidente cristiano. Sin pretenderlo Sander pone el dedo en la llaga del déficit pneumatológico que persiste y aqueja al quehacer teológico en general y sería requisito insoslayable para articular una teología de la historia: "La plenitud del ser un Dios con nosotros del Dios bíblico se cumple en el Espíritu, ya presente en la creación del mundo $(\mathrm{Gn} .1,2)$. El Espíritu representa la garantía de un Dios que compromete realmente su trascendencia con la inmanencia de lo creado. No solo 'al Espíritu debemos el que la historia

(29) Fides et ratio 17.

(30) Me permito remitir a lo que expongo en "Comentario a la ponencia 'Desafíos de la Constitución Pastoral Gaudium et Spes a la Iglesia chilena y a la Universidad Católica”, en Teología y Vida 30 (1989) 41-43. 
del Padre y del Hijo se convierta en la historia del que nos asume y salva, el que Dios entregue al Hijo al mundo sino que el Espíritu se identifica con el don que Dios hace de sí mismo precisamente como Espíritu. Así el Trascendente se hace inmanente, sin perder su trascendencia, como transformador y recreador de la inmanencia" (31). A mi parecer, la "exigencia de pluralidad en el lugar de Dios en la historia" que conjugue "los muchos signos de los tiempos y la una historia de la salvación" que plantea Sander (32) solo se puede satisfacer en la medida que se elabore esa "cristología pneumatológica" que avizora I. Congar (33). En otras palabras el estatuto teológico de una reflexión "en base a los signos de los tiempos" como la que se propone Sander depende de la consistencia pneumatológica que pueda demostrar su fundamentación.

La segunda acotación atañe a la primera "indicación” que el texto de G.S.11 le sugiere a Sander. Dado que de lo que se trata es de discernir "signos verdaderos" se impone la necesidad de elaborar una criteriología que permita distinguirlos de los falsos Este sería el "problema capital de una teología de la historia en base a los signos del tiempo". A mi entender este requerimiento condice al anterior y lo requiere como más fundamental. Así lo sugiere el mismo intento de Sander de mediar y no negar o contraponer "pluralidad y singularidad" en su proyecto de teología de la historia.

\title{
RESUMEN
}

"El autor de este artículo se reconoce en la búsqueda de una teología de los Signos de los Tiempos, desde su misma disertación doctoral hace 31 años y recoge como aportes más recientes y significativos al respecto, el de Eric Borgman y H. J. Sander. Plantea dos sugerencias que a su juicio, permitirían proyectar los aportes que entregan dichos autores".

Palabras clave: Signos de los Tiempos, Relativización, Iglesia-Mundo.

\begin{abstract}
The author of this article declares himself in search of a theology of the Signs of the Times, ever since his own doctoral dissertation 31 years ago, and selects as his most recent and significant contributors to the search Eric Borgman and H.J. Sander. He makes two suggestions that, in his judgement, permit him to incorporate the contributions of said authors into his project.
\end{abstract}

Key words: Signs of the Times, Relativization, Church-World.

(31) "La esperanza como virtud del Espíritu”, en J. Noemi, Esperanza en busca de inteligencia. Atisbos teológicos, Santiago 2005, 65.

(32) Cf. antea nota 27.

(33) El Espíritu Santo, Barcelona 1983, 598-607. 
